\title{
Stalking the elusive investment guru
}

\author{
Gabriel Lee BComm CIMA
}

$\mathrm{O}$ nce again, it is that time of the year! This time, not only is the New Year upon us, it is also the dawn of a new millennium. Because we all made it and the purported Y2K bug has not caused the bank to deposit a few million dollars extra into our bank accounts by mistake, maybe we should use this time to really take stock of our lives, start anew and recommit to working on all those New Year's resolutions.

Inevitably, 'taking stock' includes the subject of money, and someone is bound to say,

We should really look at that investment portfolio of ours and see how we have done in the past year. First, we will need to drag out all of our investment account statements for the past year, maybe all the bank statements too; sit down and sift through all those buy and sell confirmation slips; consolidate all the registered retirement savings plan accounts; determine what the portfolio started the year with and what it is worth now; and then compile, tabulate, manipulate and estimate our way into a performance number. Did I mention taking into account all the contributions and withdrawals from the investment accounts? And how about factoring in all the income generated by interest, dividends and capital gains? Okay, whose brilliant idea was this anyway? Oh, let us just forget it! If we pick up the newspaper and see how our mutual funds have done, that should give us a good enough idea of how we did overall, should it not?

Often, this scenario plays out with the portfolio being briefly scrutinized and the performance of any mutual funds owned duly noted. Inevitably, the next day, heads start to roll. Either the advisor who recommended that 'dog' of a mutual fund takes the brunt of the dissatisfaction or a decision is made to fire the bum who runs that mutual fund, leading to a reduction, sale or switch of units. After all, if the current strategy is flawed and is producing poor or substandard re- sults, something must be done to turn the proverbial boat around and get it going in the right direction, does it not? Is that not the whole reason for going through this exercise in the first place - to get rid of the lack-luster performers and clean out the pigs and dogs from our yard?

Does any of this sound familiar? Have you ever fallen into the trap of hiring or firing money managers, that is buying or selling mutual funds, based on the recent past performance of those managers?

Past experience suggests that at least some of you have contemplated using this strategy of portfolio realignment, if not actually practised it. Your rationale may not have been based entirely on your own dissatisfaction with fund performance; your investment advisor may have recommended that you switch or sell one of your underperforming funds.

In this article, I share some of the proven, procedurally prudent methods of searching for, selecting and retaining investment managers - those who you may be confident will navigate your assets astutely and conscientiously through turbulent market conditions. Because it is more challenging to rein in the risk and harness the superior returns of stock or equity managers than bond managers, the remainder of this discussion focuses on equity money managers.

\section{LET'S TALK GURU}

Many people believe that there are 'gurus' such as Warren Buffett, John Templeton and Peter Lynch with whom we can entrust our hard earned money, and that they in turn will lead us to the Mecca of high returns and low risk, with little or no effort on our part. But even these so-called gurus, with their exceptional performance records, endure periods of time during which their approaches do not work.

Consider the closed-ended mutual fund Berkshire Hathaway, basically an investment holding company run by Warren Buffett that trades on the New York Stock Ex-

Gabriel Lee is one of Canada's leading investment management consultants. In 1997, he became the eighth Canadian to receive the designation of Certified Investment Management Analyst (CIMA) from the Investment Management Consultants Association in conjunction with The Wharton Business School, University of Pennsylvania. Gabriel is currently an Associate Director with ScotiaMcLeod Inc and is in charge of the Investment Management Group in Edmonton. He can be reached at 888-814-4223, toll free, in North America.

Correspondence and reprints: Mr Gabriel Lee, Associate Director, ScotiaMcLeod Inc, Scotia Place, Main Floor, Suite M26, 10060 Jasper Avenue, Edmonton, Alberta T5J 3R8. Fax 780-413-7477, e-mail gabe_lee@scotia-mcleod.com 


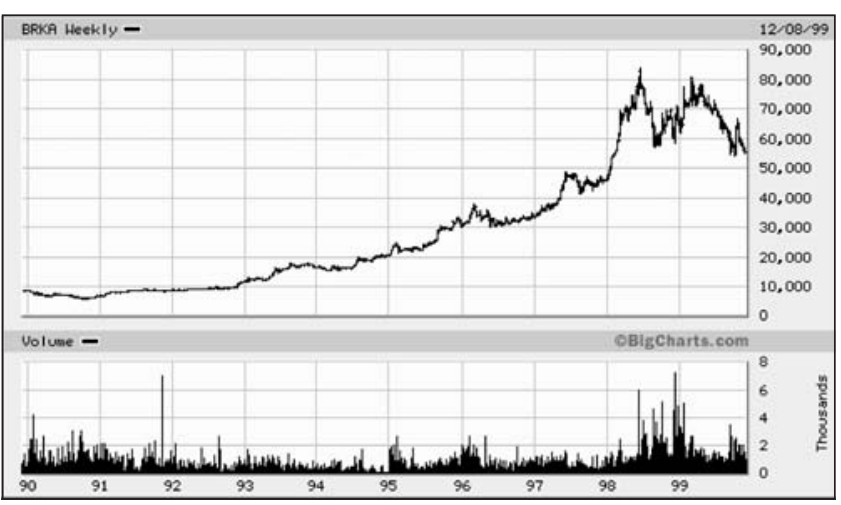

Figure 1) Berkshire Hathaway's metoric rise to stardom. BRKA Berkshire Hathaway Inc Del. Reproduced with permission from www.bigcharts.com

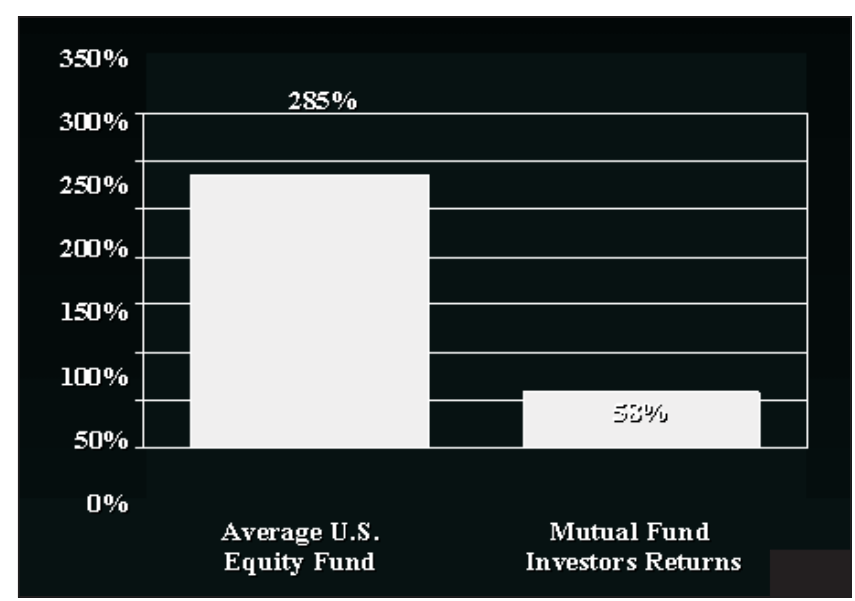

Figure 2) Investment returns versus investor returns. Reproduced with permission from Northern Trust Global Advisors. Data from reference 2

change. In 1993, an investment of US $\$ 10,000$ would have bought you one share in this company. As of early December 1999 , each share was worth US $\$ 55,000$, meaning that you would have enjoyed the awesome rate of return of nearly $28 \%$ per year, compounded annually (Figure 1).

Mr Buffett became immortalized after the publication of the book The Warren Buffett Way: Investment Strategies of the World's Greatest Investor, by Robert G Hagstrom Jr in 1994 (1). He can be considered an investment guru in every sense of the word. Warren Buffett was riding on the crest of success, notoriety and popularity that few had enjoyed before him. Retrospectively, Berkshire Hathaway was the 'hottest' investment fund out there.

So what is the problem? What can possibly be wrong with an investment that has made $28 \% /$ year for the past seven years? In short, absolutely nothing - if you bought it in January, 1993 at US $\$ 10,000$. However, if you bought the stock in mid-March, 1999 at a price of US\$81,100 instead of in 1993, your resultant rate of return would have been a sobering minus 33\% over the past nine months. Is Mr Buffett no longer a guru? Has he lost his touch? How could investing in such a pool, managed by one of the world's richest men with so much talent and foresight, ever have turned out bad? The answer to that question may lead us to an understanding of the elusive nature of the guru.

Money managers are not all created equal. Some have a unique ability to interpret market conditions and act decisively when confronted with uncertainty, and have the experience and acuity to execute precisely at the right time a majority of the time. Many managers have a proven track record, have demonstrated their ability to manage money through adverse conditions and have a proven process of security selection leading to superior results. However, I do not subscribe to the illusion that those same managers will produce large, positive rates of return every year indefinitely. The challenge, then, is to discern accurately whether the results exhibited by a given money manager are a product of investment acumen, a successful process of identifying and selecting superior investment opportunities or a byproduct of luck and fortunate timing.

\section{STOP THE INSANITY!}

If you have ever had a bout of insomnia, you may recognize this phrase used by weight loss and self-esteem guru Susan Powter in her infomercials. At times, I wish we could rewrite her script to include a commentary on 'investment insanity'.

North Americans have been raised in an environment of fast food. We demand quick fixes physically, psychologically and even spiritually. Patience and perseverance seem to be lost and forgotten virtues. We seem to have no time for such folly when faced with our overbooked schedules.

In the investment industry, this urgency manifests in the form of investors impatiently seeking short term performance results. Large or small, neophytes or veterans alike, investors often fall prey to the lure of judging investment managers purely by their short term performance numbers. With inexperienced investors, performance is often the only criterion used in their investment manager search and selection process.

This is understandable because historical performance is one of the few analytical tools easily available to most investors. This is also very unfortunate because the use of performance numbers as a measure of investment management success sometimes leads to a myopic focus on short term results, subsequently leading to flawed and counterproductive conclusions.

Dalbar (2) has shown that the average United States equity mutual fund produced a cumulative return of $285 \%$ in one 10 -year period during the study but that the average mutual fund investor in those same funds enjoyed only a $58 \%$ return (Figure 2). Why?

Investors are too often attracted to an investment with the hope of high returns and fast results. When the latest 'hot' fund or manager fails to satiate their need for performance immediately, those same investors can become critical and impatient. Inexperience and misappropriated zeal lead investors to 'buy high' when their sense of greed encourages them to choose a manager with exceptional recent performance and to 'sell low' when their patience evaporates and their fear of investment failure grips them. 
These basic human traits of fear and greed may have served us well in our evolutionary past, but inability to curb these impulses leads to unwise investment decisions. Selling current holdings to buy last year's 'hot' manager has proved to be an expensive mistake that individual investors have made again and again.

According to the Dalbar study (2), investors who buy no-load mutual funds, usually without the advice of investment advisors, typically sell their holdings within the first 18 months of purchasing them. This demonstrates a lack of the patience, confidence or fortitude required to judge the investment over at least one complete market cycle, which is usually four to six years.

This is understandable, particularly if the investor bought the fund impulsively because they had not sought out or been provided with the necessary quantitative and qualitative selection criteria. If a purchaser is not confident in their initial selection of a particular mutual fund, the people managing that fund, and the timing and appropriateness of the purchase, it is not surprising that a subsequent 'knee-jerk' decision to sell might precipitate.

Unfortunately, all too often investment management decisions are made in the 'spur of the moment', usually in a state of emotional distress or elation.

\section{HERE IS WHAT NOT TO DO}

As I suggested in previous articles, successful investors learn to avoid making large mistakes on their portfolio. Such mistakes are identified below.

Attempting to select a money manager without first having developed an investment policy: One cannot abdicate the responsibility of setting goals, objectives and guidelines with which to manage a portfolio. "The plan - Formalizing your unique "investment policy"' (3), highlighted the importance of clearly identifying and quantifying the parameters of an investment portfolio. Needless to say, a manager search is futile without the guidance of a well conceived plan of execution. An investor attempting to choose a money manager without an investment policy statement is analogous to a producer holding a casting call for a new play before a script is ever written. How can you know what talent to look for?

Setting unrealistic performance expectations: Even gurus have poor years. Chasing the latest returns without understanding why they may have occurred can lead to disappointing results. I have seen that twenty-eight per cent annually over seven years does not guarantee exceptional performance in the following year. Unfortunately, the heavy flow of capital into last year's 'hot' managers on an after-the-fact basis, and the subsequent disappointing results, demonstrates this investor axiom time and time again.

Neglecting to use style diversification within an asset class: Style refers to a money manager's chosen area of specialization. The particular style practised by a money manager may be analogous to the specialty practised by a medical doctor. A growth-style stock manager tends to focus on companies with superior prospects for earnings and expansion. Value managers, on the other hand, favour companies that are selling be- low their intrinsic worth. It may make sense to diversify into both growth and value styles within the stock component of a portfolio because employing different investment styles can reduce fluctuations in returns. Diversification helps reduce risk, whether it is applied to the number of stocks held, managers employed or asset classes used. Do not, however, simply choose a large number of managers in an attempt to make use of this strategy because all of them may be employing similar styles of investing. More on style later.

Selecting money managers without following a due diligence checklist: Selecting money managers without following a due diligence checklist can lead to a host of related mistakes: performance being compared to irrelevant investment benchmark or indexes (such as comparing an international equity manager's performance with that of the Toronto Stock Exchange index); peer comparisons being overlooked (or not comparing the risk and returns of a manager to its peers with the same investment objectives); and other important search criteria being overlooked (resulting in, for example, duplication of managers with the same or similar styles of investing).

\section{STYLE MATTERS}

Unfortunately, the stock market is not a machine that moves in regular and predictable patterns. If it were, everyone could rely on executing one set of governing principles that would ultimately lead to success and financial fulfillment. The concept of an 'efficient market' dictates that if one approach were clearly superior, everyone would quickly embrace and adopt it, and it would inevitably lose its advantage.

Accomplished money mangers each have their own distinct, well articulated philosophy about how money is made in the market. Equally important is that each has the conviction to stick with that philosophy through thick and thin. Because of this adherence to their chosen investment approaches, such managers inevitably encounter times of poor performance and uninspired results

As I alluded to above, most of the philosophies of equity managers fall somewhere on a continuum between the following two primary 'style' types:

- Growth managers tend to choose more exciting, innovative companies with leadership positions in their markets - companies whose stocks can soar if conditions are right. Growth stocks are those with higher than market (measured against the Standard \& Poor 500 or Toronto Stock Exchange 300 stock index) price to book value ratios, higher price to earnings ratios and lower than market dividend yields. Some well known companies that fall into the category of growth stocks are Microsoft, Wal-Mart, Pfizer and Nortel. Since 1994, growth stocks have dominated the market in the United States, and growth managers have basked in the limelight of success, enjoying frequent appearances on talk shows and interview requests.

- Value managers tend to look for companies that are in a temporary slump, possess hidden assets or are in mature 


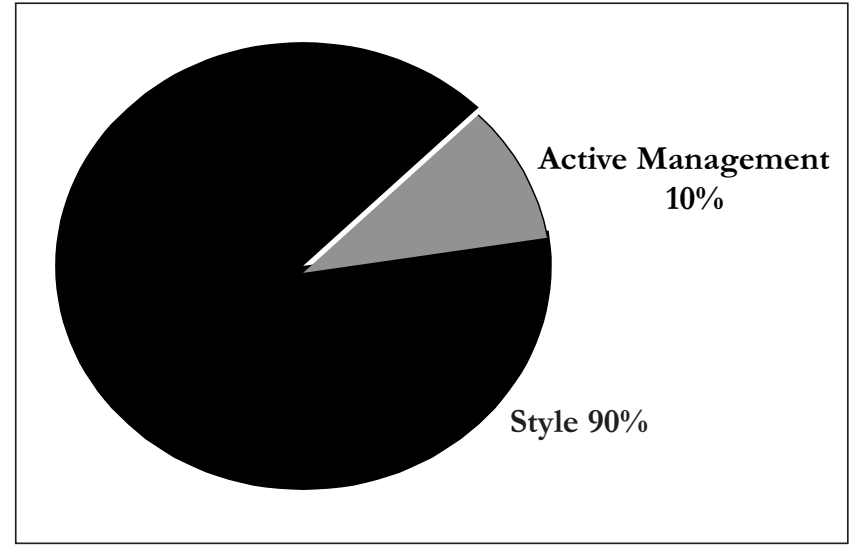

Figure 4) The importance of style. Reproduced with permission from Northern Trust Global Advisors. Data from reference 6

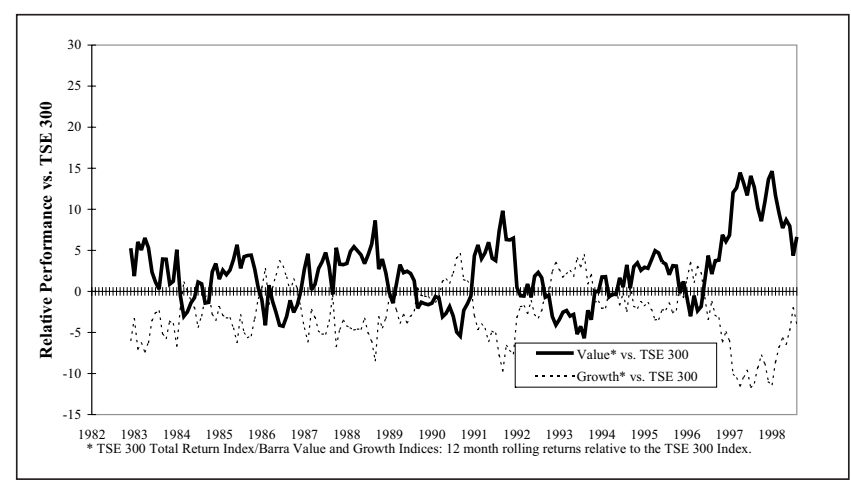

Figure 3) Canadian value stocks versus growth stocks. TSE Toronto Stock Exchange

industries unappreciated by analysts on Wall Street or Bay Street. Value stocks are those with lower than market price to book ratios, price to earnings ratios and higher than market dividend yields. Phillip Morris, Xerox, Maytag and Scotiabank are examples of value stocks. In stark contrast to the trend set by American markets, value stocks in Canada far outperformed Canadian growth companies from mid-1995 to mid-1997 (Figure 3).

Although these are the primary style types of investment managers, they are by no means the only styles available to the public. Of the myriad of styles of managers available, the ones most commonly used by Canadian investors are small, medium and large capitalization managers (each type available in growth as well as value styles); core yield managers; international managers; real estate managers; and hedge alternatives managers, followed by the extreme ends of the growth and value spectrum - managers who are either momentum or contrarian based.

Why is any of this important in conducting manager searches? An equity manager's investment style is by far the primary determinant of their short term performance, meaning that it is far more important which style(s) you select than which manager(s) you select (Figure 4). Next to asset allocation, discussed in my article entitled "Common mis-

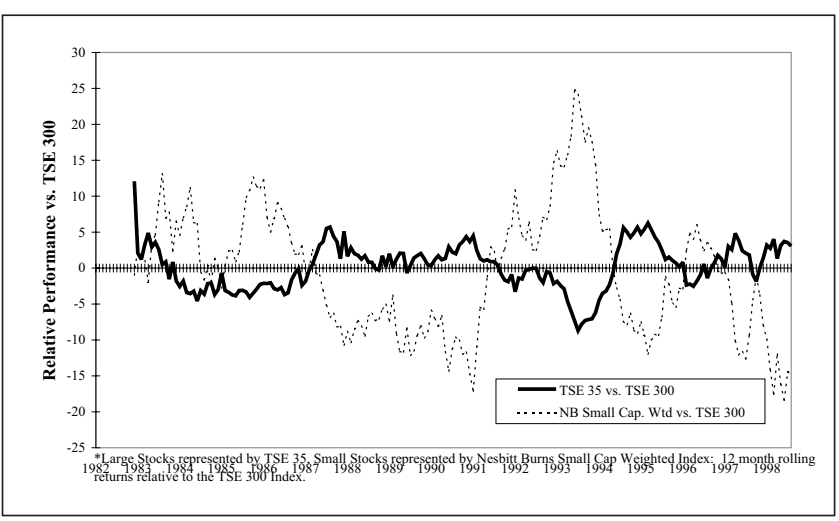

Figure 5) Canadian large stocks versus small stocks. NB Small Cap Wtd Nesbitt Burns Small Cap Weighted Index; TSE Toronto Stock Exchange

takes of affluent investors and how to avoid them" (4), style allocation may be an investor's most important decision.

As a practical example, consider the historical trend of contrasting performance patterns demonstrated by Canadian value stocks versus Canadian growth stocks over the past two decades (Figure 3). If one were to look only at the short term performance of a particular manager as a selection criterion, the wrong conclusion would likely be drawn about the capabilities of that manager. In other words, the worst growth manager may at times outperform the best value manager and vise versa.

Finally, note the counter-cyclical nature of historical returns when comparing large capitalization Canadian stocks with small capitalization Canadian stocks (Figure 5). These styles serve to counterbalance one another in a similar way that a value bias offsets a growth bias. In truth, the correct identification and interpretation of these cycles should not prompt an astute investor to eliminate completely one style of investment or another. One may seek merely to overweight one bias more than another to attempt to maximize returns.

Overall, relying on just one style of money management results in a significant degree of volatility because that style goes into and out of favour. Knowing the style as well as the trend of that style will prove to be an invaluable asset in selection of a money manager and in the ongoing decisions to continue with or to replace that manager.

\section{WHAT IS NEXT?}

Once a working understanding is achieved of how investment styles and cycles interact within a portfolio, initial manager selections may be made, and detailed due diligence and analysis rendered. At this point, most clients hand the remaining responsibilities to a consultant for further distillation, and sit back and await the final proposal.

I say 'consultants' because the information, time and expertise required to proceed past this juncture is beyond the scope of most individual investors. Many consultants employ the following analysis to distill further the most ideal investment management candidates for a client's portfolio (Figure 
6). The 'four Ps' refer to people, philosophy, process and performance, and serve to accentuate the successful candidates and cast an unsavory pallor on the rest.

\section{WHAT SHOULD INVESTORS DO?}

Because it is impossible to predict accurately future investment results based on past returns, individual investors can follow many of the same criteria that large sophisticated pension plans use when selecting the managers for their portfolios, including:

- Selecting experienced, disciplined managers who use a distinct, well articulated philosophy of investing through changing market conditions, a disciplined investment strategy and process that have performed well over a long period of time;

- Using mangers that use concentrated portfolios. Select managers who limit the number of holdings in their portfolios so that they invest only in their very best ideas;

- Making sure that it is very unlikely that the fund will change managers any time in the foreseeable future. In its purest essence, selecting a money manager is simply buying the skills of a particular manager or portfolio team. If that manager leaves or the team chemistry is altered, a completely different fund with different characteristics and returns may result. Consider hiring only managers that own their own firms or at least have large equity stakes in the companies for which they work. Either way, the less likely the possibility of change in personnel, the better.

- Selecting only managers who do not have too much money to manage. A recent study conducted by Hurley et al (5) clearly shows that investing money is a diseconomy of scale. That is, the more money that a manager has under management, the harder it is for him or her to get superior returns. In Canada, where equity markets are small and trading relatively light compared with those in the United States or numerous other foreign markets, the ability of a manager to buy and sell stocks without altering the price of that stock are limited. Canadian equity managers who manage more than $\$ 1$ billion to $\$ 1.5$ billion, depending on their style of management, seem to reach a threshold where size becomes a problem.

In general, the use of multiple managers with multiple styles put through the aforementioned screens should produce the best results.

\section{IN THE NEXT ARTICLE}

After all the exhaustive research and contemplation, hopefully, a group of uniquely skilled and tightly focused money managers are retained to actualize your financial aspirations. If you have followed all the steps of the investment management consulting process, as outlined in my previous articles,

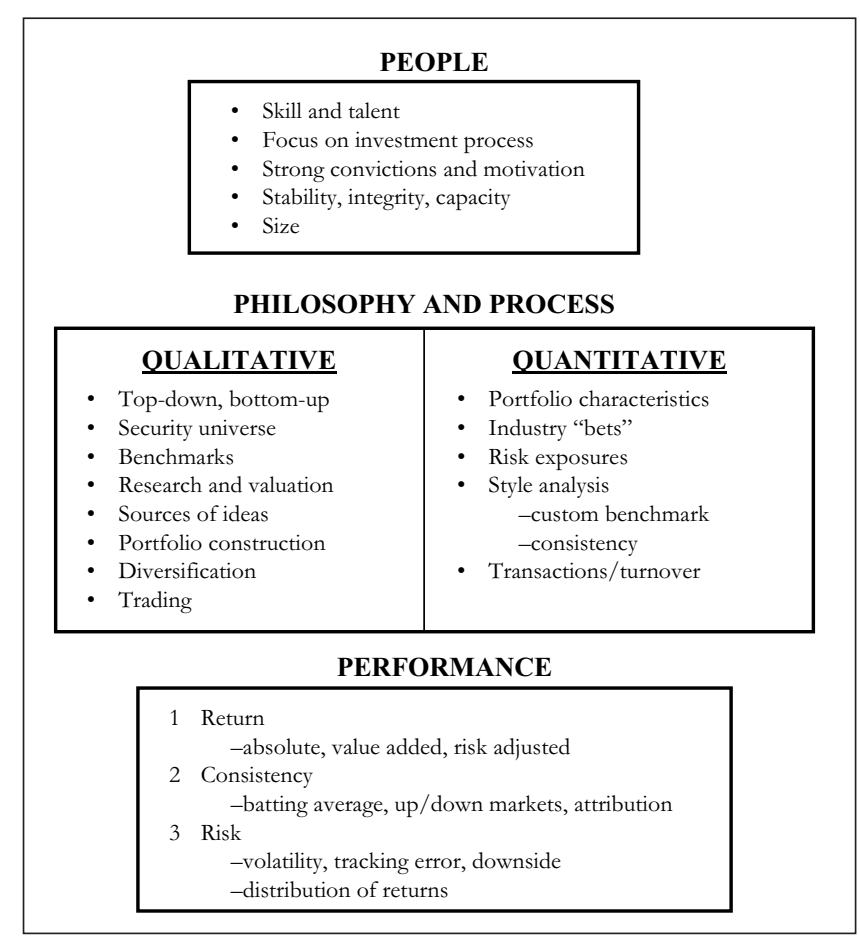

Figure 6) The manager selection and due diligence process

the likelihood of you making a significant and costly mistake will be minimized.

Now that you have hired these managers, does it mean that they will always be the best candidates to steward your financial aspirations? Of course not. There are many reasons to reconsider working with a particular manager. A change in your investment objectives upon retirement, a period of unexplainable performance characteristics whether they be exceptionally good or exceptionally poor, or a change in a manager's personnel mix all call for additional scrutiny to be placed on existing managers.

In the next article, I will complete the investment management consulting odyssey by describing the last and final step of the six-step process - monitoring and evaluating your portfolio on an on-going basis. It will be entitled "The vigilant sentinel".

In the meantime, treat your current stable of managers kindly because your search for the elusive guru may lead you right back to your own portfolio.

\section{REFERENCES}

1. Hagstrom RG Jr. The Warren Buffett Way: Investment Strategies of the World's Greatest Investor. New York: John Wiley \& Sons, 1994.

2. <Http://www.dalbar.com/quantitative_analysis.shtml> Boston: Dalbar, Inc, 1997.

3. Lee G. The plan - Formalizing your unique 'investment policy'. Can J Gastroenterol 1999;13:779-83.

4. Lee G. Common mistakes of affluent investors and how to avoid them. Can J Gastroenterol 1999;13:521-4.

5. Hurley MP, Fuller TG, Kanner YN. The Future of the Financial Advisory Business and the Delivery of Advice to the Semi-Affluent Investor. Dallas: Undiscovered Managers, 1998.

6. Sharpe, WF. Asset allocation: management style and performance measurement. J Portfolio Manage 1992;18:7-19. 


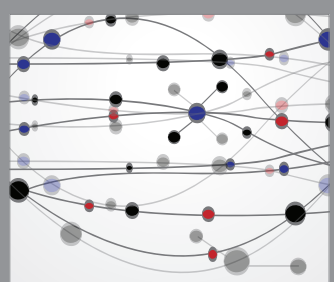

The Scientific World Journal
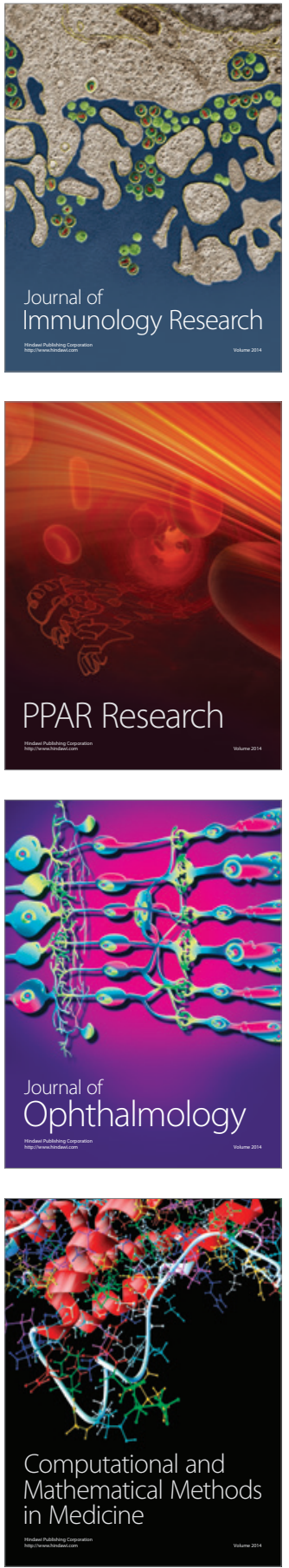

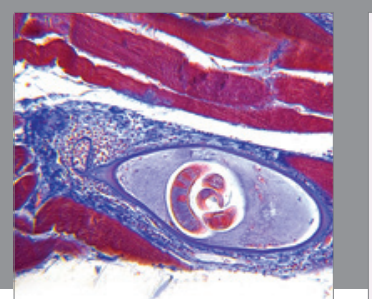

Gastroenterology Research and Practice

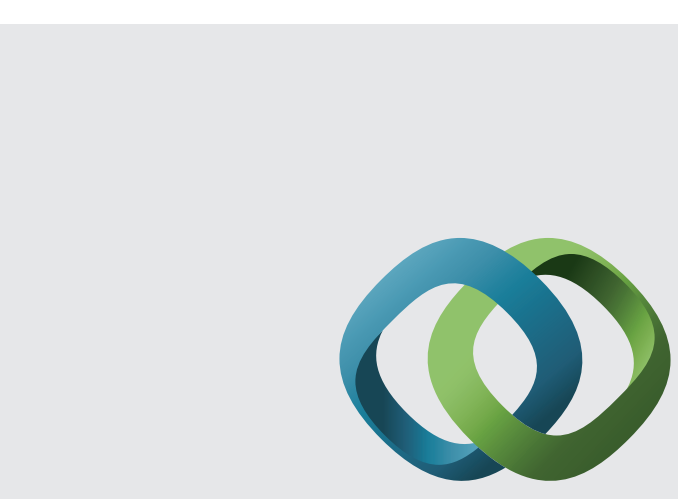

\section{Hindawi}

Submit your manuscripts at

http://www.hindawi.com
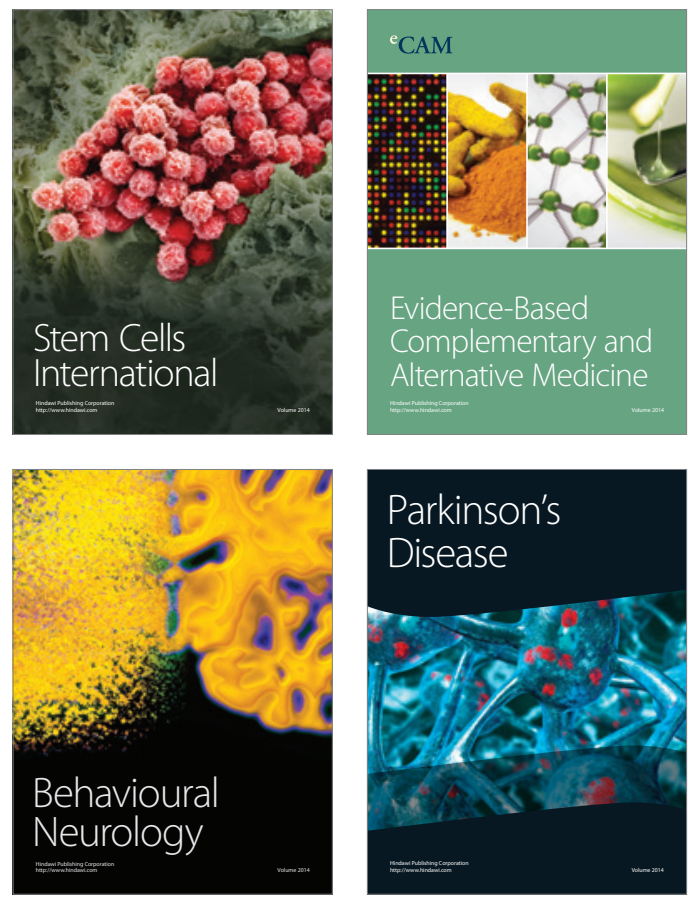
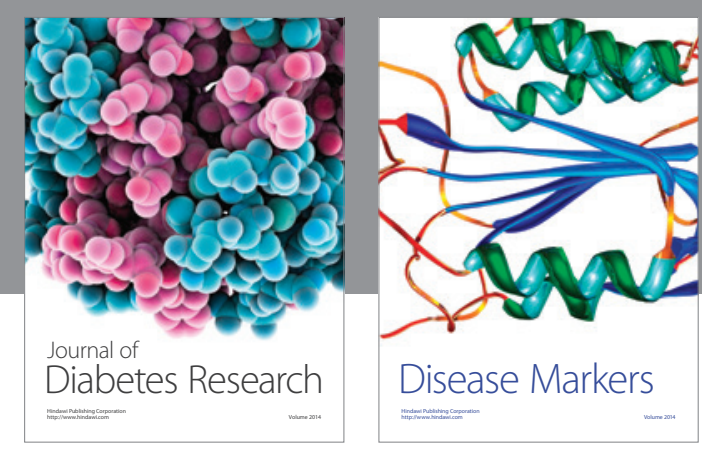

Disease Markers
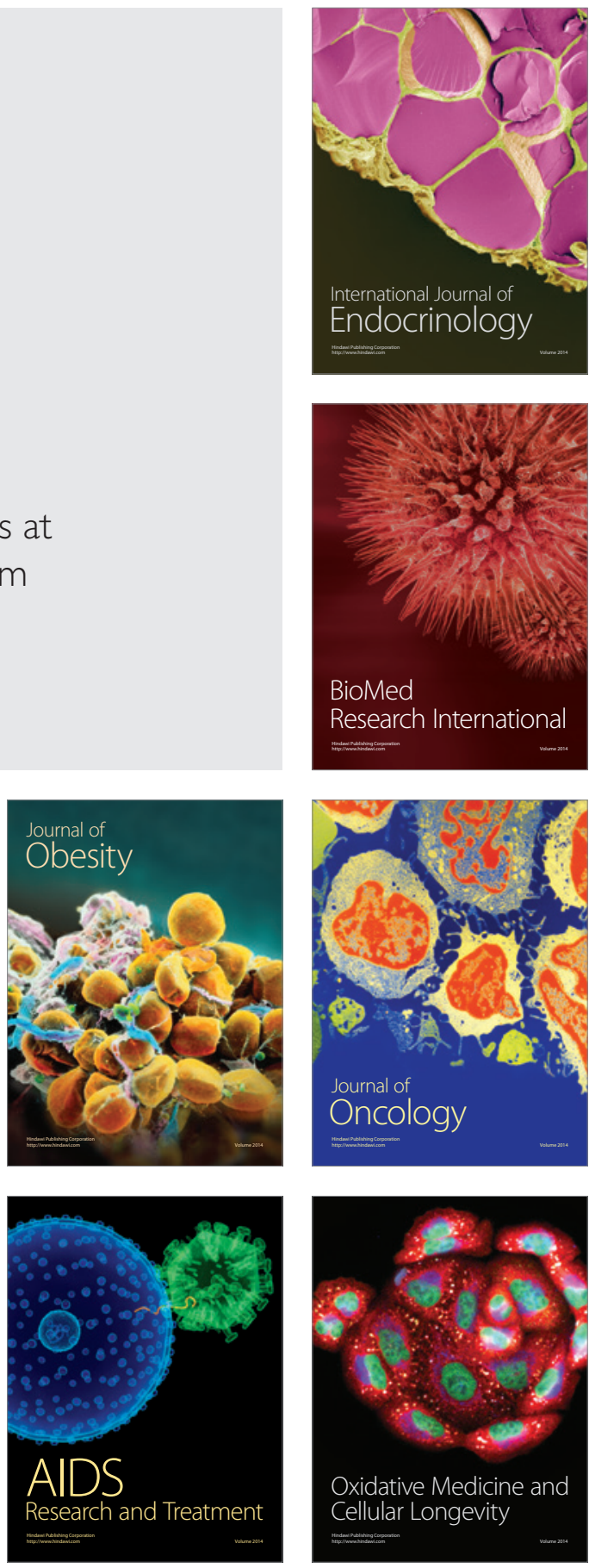